\title{
Population-based survey of the prevalence of lower urinary tract symptoms in adolescents with and without psychotropic substance abuse
}

\author{
YH Tam *, CF Ng, YS Wong, Kristine KY Pang, YL Hong, WM Lee, PT Lai
}

\section{A B S T R A C T}

Objective: To investigate the prevalence of lower urinary tract symptoms in adolescents and the effects of psychotropic substance use.

Methods: This was a population-based crosssectional survey using a validated questionnaire in students from 45 secondary schools in Hong Kong randomly selected over the period of January 2012 to January 2014. A total of 11938 secondary school students (response rate, 74.6\%) completed and returned a questionnaire that was eligible for analysis. Individual lower urinary tract symptoms and history of psychotropic substance abuse were documented.

Results: In this study, 11617 non-substance abusers were regarded as control subjects and 321 (2.7\%) were psychotropic substance users. Among the control subjects, 2106 (18.5\%) had experienced at least one lower urinary tract symptom with urinary frequency being the most prevalent symptom (10.2\%). Females had more daytime urinary incontinence $(\mathrm{P}<0.001)$ and males had more voiding symptoms $(\mathrm{P}=0.01)$. Prevalence of lower urinary tract symptoms increased with age from $13.9 \%$ to $25.8 \%$ towards young adulthood and age of $\geq 18$ years $(\mathrm{P}<0.001)$. Among the substance users, ketamine was most commonly abused. Substance users had significantly more lower urinary tract symptoms

This article was published on 12 Aug 2016 at www.hkmj.org. than control subjects $(\mathrm{P}<0.001)$. In multivariate analysis, increasing age and psychotropic substance abuse increased the odds for lower urinary tract symptoms. Non-ketamine substance users and ketamine users were respectively 2.8 -fold (95\% confidence interval, 2.0-3.9) and 6.2-fold (4.1-9.1) more likely than control subjects to develop lower urinary tract symptoms. Females (odds ratio=9.9; 95\% confidence interval, 5.4-18.2) were more likely to develop lower urinary tract symptoms than males (4.2; 2.5-7.1) when ketamine was abused.

Conclusions: Lower urinary tract symptoms are prevalent in the general adolescent population. It is important to obtain an accurate history regarding psychotropic substance use when treating teenagers with lower urinary tract symptoms.

\section{Hong Kong Med J 2016;22:454-63}

DOI: 10.12809/hkmj154806

${ }^{1}$ YH Tam *, FHKAM (Surgery)

${ }^{2}$ CF Ng, FHKAM (Surgery)

${ }^{1}$ YS Wong, FHKAM (Surgery)

${ }^{1}$ KKY Pang, FHKAM (Surgery)

${ }^{1}$ YL Hong, MSc

${ }^{2}$ WM Lee, MSc

PT Lai, BN

${ }^{1}$ Division of Paediatric Surgery and Paediatric Urology

Division of Urology

Department of Surgery, Prince of Wales Hospital, The Chinese University of Hong Kong, Shatin, Hong Kong

* Corresponding author: pyhtam@surgery.cuhk.edu.hk

\section{New knowledge added by this study \\ Prevalence of lower urinary tract symptoms (LUTS) increases consistently from onset of adolescence towards adulthood. Psychotropic substance abuse, particularly ketamine, is associated with an increased risk of developing LUTS in adolescents. Girls are more susceptible than boys if ketamine is abused. \\ Implications for clinical practice or policy \\ It is important to obtain an accurate history regarding psychotropic substance use when treating teenagers with LUTS.}

\section{Introduction}

Lower urinary tract symptoms (LUTSs) are prevalent worldwide. An estimated $45.2 \%$ of the 2008 worldwide population aged $\geq 20$ years are affected by at least one LUTS. ${ }^{1}$ Large-scale population-based survey has reported that LUTS prevalence increases with advancing age up to $60 \%$ at the age of 60 years. $^{2}$ Evaluation and treatment of LUTS for the general population have incurred significant costs to the health care system. In children, the association of LUTS with urinary tract infection, persistent vesicoureteric reflux, renal scarring, and constipation have drawn substantial attention over the years., ${ }^{3,4}$ Among various LUTSs, urinary incontinence (UI) has been most extensively investigated in children with the reported prevalence varying from $1.8 \%$ to 
$20 \% .{ }^{5}$ Previous studies of the prevalence of individual LUTS using the International Children's Continence Society (ICCS) definitions ${ }^{6}$ have focused primarily on pre-adolescent children in primary schools. ${ }^{7-10}$ To date, no large-scale studies have investigated the prevalence of LUTSs in adolescents.

Psychotropic substance use among adolescents is a growing concern worldwide and creates psychosocial, security, and health care issues. In recent years, ketamine abuse has been found to cause severe LUTSs and Hong Kong is one of the earliest countries/regions to report the newly established clinical entity of ketamine-associated uropathy. ${ }^{11-13}$ Ketamine is the most popular psychotropic substance being abused by people aged $<21$ years in our society. ${ }^{14}$ The aim of the present study was to investigate the prevalence of LUTSs in our adolescents and the differences between those with and without psychotropic substance use.

\section{Methods}

\section{Study design, sample size estimation, and participant recruitment}

This was a cross-sectional questionnaire survey that recruited adolescents from secondary schools serving Hong Kong local residents during the period of January 2012 to January 2014. There were almost 500 secondary schools in Hong Kong serving approximately 470000 adolescents in 2009/10. Based on the data of children and young adults available in the literature, ${ }^{2,9}$ we assumed the prevalence of LUTSs among our adolescents to be $20 \%$. A study sample of 6050 participants would be required to allow an error of $\pm 1 \%$. Government sources suggested $2.3 \%$ of our secondary school students used psychotropic substance in 2011/12. ${ }^{15}$ We assumed the prevalence of LUTSs among those secondary students using psychotropic substance was $15 \%$ higher than in normal subjects. In order to detect a difference with a type 1 error of 0.05 and a power of 0.8 , a sample size of 4500 participants would be required. Based on the above two assumptions and a predicted response rate of $50 \%$ to $60 \%$, we determined that a potential target of not less than 10000 participants would be required.

In the selection of schools we included all government, aided, and Direct Subsidy Scheme schools. Private international schools and special schools were excluded. Co-educational, boys', and girls' schools were included. The list of secondary schools was provided by the Education Bureau and schools were grouped into 18 geographical districts. As the prevalence of psychotropic substance use might vary significantly between schools, we arbitrarily determined to recruit participants from not less than $8 \%$ to $10 \%$ of the secondary schools in order to reduce the sampling bias.

\section{曾經和未有濫用精神藥物的青少年的下尿路症狀} 發病率：以人口為基礎的調查

譚煜謙、吳志輝、黃婉珊、彭潔儀、匡若琳、李慧敏、黎珮德

目的：探討青少年下尿路症狀發病率及濫用精神藥物的影響。

方法：這研究使用已驗證的問卷進行横斷面以人口為基礎的調 查, 2012 年1月至2014年1月期間隨機抽選香港45間中學的學生

總計共 11938 名中學生完成及交回有效問卷作分析用途, 回覆率達 $74.6 \%$, 並記錄參與者的個人下尿路症狀及精神藥物濫用史

結果：受訪者中有 11617 人未曾使用精神藥物並被列為對照組，另 321 人 $(2.7 \%)$ 曾濫用精神藥物。對照組中 2106 人（18.5\%）曾經有 最少一項下尿路症狀, 以尿頻最為常見 $(10.2 \%)$ 。女性較多出現日 間小便失禁 $(\mathrm{P}<0.001)$ 而男性有較多排尿症狀（ $\mathrm{P}=0.01 ）$ 。隨着年 齡上升至青年期（18歲或以上），下尿路症狀發病率由 $13.9 \%$ 上升至 $25.8 \% （ \mathrm{P}<0.001 ） 。$ 氯胺酮是曾使用精神藥物的受訪者中最常被濫 用的精神藥物。曾使用精神藥物的受訪者比對照組明顯有較多下尿路 症狀 $(\mathrm{P}<0.001)$ 。多元分析顯示年齡上升及曾經濫用精神藥物會增 加下尿路症狀的比值。濫用非氯胺酮的精神藥物受訪者及濫用氯胺酮 的受訪者出現下尿路症狀的機會分別是對照組的 2.8 倍 $(95 \%$ 置信區 間：2.0-3.9）及6.2倍（95\%置信區間：4.1-9.1）。濫用氯胺酮後, 女 性（比值比=9.9；95\%置信區間：5.4-18.2）比男性 ( $4.2 ； 2.5-7.1)$ 有更大機會出現下尿路症狀。

結論：下尿路症狀在一般青少年間很常見。治療出現下尿路症狀的青 少年時獲取準確的精神藥物濫用史十分重要

The random selection process started with drawing a district followed by a school within the selected district. Based on a rough estimation of population distribution, we intended to select schools from Hong Kong Island (HKI), Kowloon (Kln), and New Territories (NT) in an approximate ratio of $1: 2: 3$. We invited the selected schools to participate in the study. If the invitation was declined, the next school following the drawing sequence would be contacted. The above procedure was repeated until the target sampling size was reached. Finally, 45 out of 121 schools were selected and approached, and agreed to participate in the study (HKI, $n=7 ; \mathrm{Kln}$, $\mathrm{n}=13$; NT, $\mathrm{n}=25$ ) giving a potential target of 16000 participants.

The grades/classes of students participating in the survey from each school were not randomly selected but were determined after discussion and mutual agreement with the school management. In order to avoid the possible bias of intentional selection or exclusion of a particular class of students, school management was invited to express their preferences about which grade/grades of students would participate provided that all students of the selected grade/grades participated. Although we tried to avoid over-representation of a particular grade of students by making some suggestions to the school management, their preferences were always respected and accepted. Of the 45 participating 
schools, we recruited two or three grades of Form 1-3 students, two or three grades of Form 4-6 students, and all the students in 18, 10, and 8 schools, respectively. In the remaining nine schools, we recruited only one grade of their students.

\section{Study measures}

The measuring tool was an anonymous self-reported questionnaire accompanied by an information sheet. In both the information sheet and the questionnaire, we stated clearly that participation in the study was voluntary and consent to participate was presumed on receipt of a completed questionnaire that was returned in the envelope provided. Individuals who did not consent to participate were told to disregard the questionnaire. The questionnaire consisted of three parts: demographic data on gender and age, LUTS assessment, and history of psychotropic substance use (Appendix).

Age was divided into four categories: <13, $13-15,16-17$, and $\geq 18$ years. Participants were asked to respond to an 8-item LUTS assessment that included storage symptoms (urinary frequency, urgency, nocturia, and daytime UI), voiding symptoms (intermittent stream, straining, and dysuria), and post-micturition symptom (incomplete emptying). The recall period was the last 4 weeks. The LUTS questions were adapted from the Hong Kong Chinese version of International Prostate Symptom Score questionnaire that has been validated to assess LUTSs in our local adult population. ${ }^{16} \mathrm{We}$ believed that the level of comprehension of most of our adolescent participants in secondary education was close to that of an average adult. The response options for most of the LUTSs were on a 6-point Likert scale: "never", "seldom ( $<20 \%$ of the time)", "sometimes (20-50\% of the time)", "often (50\% of the time)", "always ( $>50 \%$ of the time)", and "almost every time”. Any LUTS with frequency threshold of ' $\geq 20 \%$ of the time' was defined as being present in the study subject. Daytime UI and nocturia were assessed on a different 5-point Likert scale according to their frequency. Daytime UI and nocturia were defined as present if the study subject had $\geq 1$ to 3 times per month and $\geq 2$ times per night, respectively.,17

Responses to questions on psychotropic substance use were dichotomised as either "yes" or "no". Those with positive responses were directed to questions on the type of substance being abused, which included ketamine, ecstasy, methamphetamine, cough mixture, marijuana, and others. Participants were allowed to indicate more than one substance. According to the response to questions on psychotropic substance use, the participants were classified as control subjects or psychotropic substance users. The psychotropic substance users were further subdivided into either ketamine users or non-ketamine users.

\section{Statistical analysis}

The responses to each LUTS were dichotomised as "present" versus "absent" and prevalence rate for each LUTS was expressed in percentage with 95\% confidence interval (CI). Missing data were excluded for analysis. Chi squared and trend tests were performed in univariate analysis to compare prevalence differences between groups divided by gender, age, and psychotropic substance use. Using the outcome of "at least one LUTS", which was dichotomised into "yes" or "no", a binary logistic regression model using enter method was set up to investigate risk factors including gender, age, and psychotropic substance use. Odds ratio (OR) of "at least one LUTS" was estimated with 95\% CI for the potential risk factors. A P value of $<0.05$ was considered to be significant.

The study protocol was approved by the Joint CUHK-NTEC Clinical Research Ethics Committee.

\section{Results}

A total of 16000 questionnaires were sent to schools and 11938 were returned (estimated response rate, $74.6 \%)$ that were eligible for analysis in the study. The response rate was estimated since the number of questionnaires delivered to each school was not necessarily equal to the number of students of that school who received the questionnaire. The conduction of the survey at schools was not supervised. We were uncertain if students absent from school would receive our questionnaire. The number of questionnaires requested by each school was always rounded off to the nearest 10 and not necessarily equal to the actual number of students in the selected classes. It seems logical to assume that the actual number of students who received our questionnaires was less than 16000 and the actual response rate might be higher. There were similar numbers of males $(n=6040)$ and females $(n=5819)$ among the participants who responded to the question on gender. Among the 11938 participants, 11617 did not report use of any psychotropic substances and were defined as control subjects; $321(2.7 \%)$ participants reported to have used one or more types of psychotropic substance were defined as substance users.

Of 11617 control subjects, 2106 (18.5\%; including only the valid subjects) had experienced at least one LUTS with the symptom frequency of ' $\geq 20 \%$ of the time' in the last 4 weeks (Table 1 ). The most prevalent LUTSs were urinary frequency (10.2\%), incomplete emptying (5.4\%), and nocturia $\geq 2$ times per night (4.4\%). Daytime UI $\geq 1$ to 3 times per month was reported by $3.7 \%$ of control subjects. Females had more daytime UI than males $(5.2 \%$ vs $2.2 \% ; \mathrm{P}<0.001)$, while males had significantly more voiding symptoms and incomplete emptying. There was significant increase in the prevalence of all 
TABLE I. Prevalence of LUTS in control subjects and comparison by gender

\begin{tabular}{|c|c|c|c|c|}
\hline & \multicolumn{3}{|c|}{$\begin{array}{l}\text { No. (\%) } \\
{[95 \% \mathrm{Cl}]}\end{array}$} & \multirow[t]{2}{*}{$P$ value } \\
\hline & Total $\left(n^{\star}=11617\right)$ & Male $\left(n^{*}=5848\right)$ & Female $\left(n^{*}=5703\right)$ & \\
\hline Any LUTS & & & & 0.04 \\
\hline Yes & $\begin{array}{c}2106 / 11405(18.5) \\
{[17.7-19.2 \%]}\end{array}$ & $\begin{array}{c}1106 / 5757(19.2) \\
{[18.2-20.2 \%]}\end{array}$ & $\begin{array}{c}986 / 5584(17.7) \\
{[16.7-18.7 \%]}\end{array}$ & \\
\hline Missing & $212 / 11617$ (1.8) & $91 / 5848(1.6)$ & $119 / 5703(2.1)$ & \\
\hline Urinary frequency & & & & 0.05 \\
\hline Yes & $\begin{array}{c}1180 / 11552(10.2) \\
{[9.7-10.8 \%]}\end{array}$ & $\begin{array}{c}626 / 5816(10.8) \\
{[10.0-11.6 \%]}\end{array}$ & $\begin{array}{c}547 / 5671(9.6) \\
{[8.9-10.4 \%]}\end{array}$ & \\
\hline Missing & $65 / 11617(0.6)$ & $32 / 5848(0.5)$ & $32 / 5703(0.6)$ & \\
\hline Nocturia $\geq 2$ times per night & & & & 0.19 \\
\hline Yes & $\begin{array}{c}508 / 11537(4.4) \\
{[4.0-4.8 \%]}\end{array}$ & $\begin{array}{c}271 / 5819(4.7) \\
{[4.1-5.2 \%]}\end{array}$ & $\begin{array}{c}235 / 5656(4.2) \\
{[3.6-4.7 \%]}\end{array}$ & \\
\hline Missing & $80 / 11617(0.7)$ & $29 / 5848(0.5)$ & $47 / 5703(0.8)$ & \\
\hline Urgency & & & & 0.99 \\
\hline Yes & $\begin{array}{c}338 / 11556(2.9) \\
{[2.6-3.2 \%]}\end{array}$ & $\begin{array}{c}169 / 5817(2.9) \\
{[2.5-3.3 \%]}\end{array}$ & $\begin{array}{c}165 / 5674(2.9) \\
{[2.5-3.3 \%]}\end{array}$ & \\
\hline Missing & $61 / 11617(0.5)$ & $31 / 5848(0.5)$ & $29 / 5703(0.5)$ & \\
\hline Daytime urinary incontinence $†$ & & & & $<0.001$ \\
\hline Yes & $\begin{array}{c}160 / 4302(3.7) \\
{[3.2-4.3 \%]}\end{array}$ & $\begin{array}{c}47 / 2109(2.2) \\
{[1.6-2.9 \%]}\end{array}$ & $\begin{array}{c}113 / 2165(5.2) \\
{[4.3-6.2 \%]}\end{array}$ & \\
\hline Missing & $23 / 4325(0.5)$ & $11 / 2120(0.5)$ & $12 / 2177(0.6)$ & \\
\hline Intermittent voiding & & & & 0.01 \\
\hline Yes & $\begin{array}{c}320 / 11505(2.8) \\
{[2.5-3.1 \%]}\end{array}$ & $\begin{array}{c}176 / 5791(3.0) \\
{[2.6-3.5 \%]}\end{array}$ & $\begin{array}{c}143 / 5649(2.5) \\
{[2.1-2.9 \%]}\end{array}$ & \\
\hline Missing & $112 / 11617(1.0)$ & $57 / 5848(1.0)$ & $54 / 5703(0.9)$ & \\
\hline Straining & & & & $<0.001$ \\
\hline Yes & $\begin{array}{c}231 / 11531(2.0) \\
{[1.7-2.2 \%]}\end{array}$ & $\begin{array}{c}150 / 5812(2.6) \\
{[2.2-3 \%]}\end{array}$ & $\begin{array}{c}78 / 5671(1.4) \\
{[1.1-1.7 \%]}\end{array}$ & \\
\hline Missing & $68 / 11617(0.6)$ & $36 / 5848(0.6)$ & $32 / 5703(0.6)$ & \\
\hline Dysuria & & & & 0.001 \\
\hline Yes & $\begin{array}{c}210 / 11526(1.8) \\
{[1.6-2.1 \%]}\end{array}$ & $\begin{array}{c}130 / 5806(2.2) \\
{[1.9-2.6 \%]}\end{array}$ & $\begin{array}{c}78 / 5655(1.4) \\
{[1.1-1.7 \%]}\end{array}$ & \\
\hline Missing & $91 / 11617(0.8)$ & $42 / 5848(0.7)$ & 48/5703 (0.8) & \\
\hline Incomplete emptying & & & & 0.001 \\
\hline Yes & $\begin{array}{c}628 / 11571(5.4) \\
{[5.0-5.8 \%]}\end{array}$ & $\begin{array}{c}356 / 5826(6.1) \\
{[5.5-6.7 \%]}\end{array}$ & $\begin{array}{c}266 / 5680(4.7) \\
{[4.1-5.2 \%]}\end{array}$ & \\
\hline Missing & 46/11 $617(0.4)$ & $22 / 5848(0.4)$ & 23/5703 (0.4) & \\
\hline
\end{tabular}

Abbreviations: $\mathrm{Cl}=$ confidence interval; LUTS = lower urinary tract symptoms

* Subgroups $n$ might or might not equal to total $n$ due to missing values

† Due to printing error, only 4452 of the I। 938 eligible questionnaires included the question on daytime urinary incontinence

LUTSs except for daytime UI across the age-groups substance $(\mathrm{n}=139 ; 45.6 \%)$, followed by cough from $<13$ years to the young adulthood age-group of mixture $(n=96 ; 31.5 \%)$, ecstasy $\quad(n=77 ; 25.2 \%)$, $\geq 18$ years (Table 2 ).

Compared with control subjects, the $(n=70 ; 23.0 \%)$. Of ketamine users, 60.7\% had at least psychotropic substance users experienced one LUTS. Comparing the ketamine users with significantly more LUTSs in all areas (Table 3). Of other non-ketamine substance users, the former the 321 substance abusers, 305 responded to the experienced significantly more LUTSs in all areas question about types of psychotropic substance except for daytime UI, though for which a higher abused. Ketamine was the most commonly abused prevalence was still observed. Female ketamine 
TABLE 2. Comparison of LUTS in control subjects by age

\begin{tabular}{|c|c|c|c|c|c|}
\hline & \multicolumn{4}{|c|}{ Age (years), No. (\%) } & \multirow[t]{2}{*}{$P$ value } \\
\hline & $<13\left(n^{*}=1545\right)$ & $13-15\left(n^{*}=5858\right)$ & $16-17\left(n^{\star}=3525\right)$ & $\geq 18\left(n^{*}=602\right)$ & \\
\hline Any LUTS & & & & & $<0.001$ \\
\hline Yes & 210/1514 (13.9) & $971 / 5746(16.9)$ & 750/3469 (21.6) & 153/594 (25.8) & \\
\hline Missing & $31 / 1545(2.0)$ & $112 / 5858(1.9)$ & $56 / 3525(1.6)$ & 8/602 (1.3) & \\
\hline Urinary frequency & & & & & $<0.001$ \\
\hline Yes & $90 / 1534(5.9)$ & $504 / 5826(8.7)$ & 476/3506 (13.6) & $98 / 601$ (16.3) & \\
\hline Missing & $11 / 1545(0.7)$ & $32 / 5858(0.5)$ & $19 / 3525(0.5)$ & $1 / 602(0.2)$ & \\
\hline Nocturia $\geq 2$ times per night & & & & & $<0.001$ \\
\hline Yes & $61 / 1533(4.0)$ & 232/5814 (4.0) & $165 / 3508(4.8)$ & $44 / 600(7.4)$ & \\
\hline Missing & $12 / 1545(0.8)$ & 44/5858 (0.8) & $17 / 3525(0.5)$ & 2/602 (0.3) & \\
\hline Urgency & & & & & 0.001 \\
\hline Yes & 33/1531 (2.2) & $158 / 5834(2.7)$ & 107/3506 (3.1) & $34 / 599(5.7)$ & \\
\hline Missing & $14 / 1545(0.9)$ & 24/5858 (0.4) & $19 / 3525(0.5)$ & $3 / 602(0.5)$ & \\
\hline Daytime urinary incontinence $\dagger$ & & & & & 0.60 \\
\hline Yes & $13 / 462(2.8)$ & 85/2264 (3.8) & 47/1241 (3.8) & $14 / 299(4.7)$ & \\
\hline Missing & $8 / 470(1.7)$ & $12 / 2276(0.5)$ & 3/1244 (0.2) & 0/299 (0) & \\
\hline Intermittent voiding & & & & & $<0.001$ \\
\hline Yes & $32 / 1530(2.1)$ & $136 / 5799(2.3)$ & 116/3497 (3.3) & 31/597 (5.2) & \\
\hline Missing & $15 / 1545(1.0)$ & $59 / 5858(1.0)$ & 28/3525 (0.8) & $5 / 602(0.8)$ & \\
\hline Straining & & & & & $<0.001$ \\
\hline Yes & $14 / 1534(0.9)$ & 93/5826 (1.6) & $89 / 3503$ (2.5) & 28/599 (4.7) & \\
\hline Missing & $11 / 1545(0.7)$ & $32 / 5858(0.5)$ & 22/3525 (0.6) & 3/602 (0.5) & \\
\hline Dysuria & & & & & $<0.001$ \\
\hline Yes & $22 / 1529(1.4)$ & $89 / 5808$ (1.5) & 66/3502 (1.9) & 28/601 (4.7) & \\
\hline Missing & $16 / 1545$ (1.0) & $50 / 5858(0.9)$ & $23 / 3525(0.7)$ & $1 / 602(0.2)$ & \\
\hline Incomplete emptying & & & & & $<0.001$ \\
\hline Yes & 68/1535 (4.4) & 281/5839 (4.8) & 219/3511 (6.2) & $51 / 600(8.5)$ & \\
\hline Missing & $10 / 1545(0.6)$ & $19 / 5858(0.3)$ & $14 / 3525(0.4)$ & 2/602 (0.3) & \\
\hline
\end{tabular}

Abbreviation: LUTS = lower urinary tract symptoms

* Subgroups $n$ might or might not equal to total $n$ due to missing values

+ Due to printing error, only 4452 of the I| 938 eligible questionnaires included the question on daytime urinary incontinence

users appeared to be more affected by LUTS than males (Table 4).

In multivariate analysis, increasing age and psychotropic substance use were found to increase the odds for experiencing at least one LUTS. With reference to age of $<13$ years, the ORs of experiencing at least one LUTS at age $13-15,16-17$, and $\geq 18$ years were 1.3 (95\% CI, 1.1-1.5), 1.7 (95\% CI, 1.4-2.0), and 2.1 (95\% CI, 1.7-2.7), respectively. With reference to the control subjects, the ORs of experiencing at least one LUTS were 2.8 (95\% CI, 2.0-3.9) for those who used substances other than ketamine, and 6.2 (95\% CI, 4.1-9.1) for those who used ketamine. When assessing the two genders separately in multivariate analysis, female ketamine users were 9.9-fold (95\% CI, 5.4-18.2) and male ketamine users were 4.2-fold
(95\% CI, 2.5-7.1) more likely than their non-abuser counterparts to develop LUTSs.

\section{Discussion}

Large-scale population-based surveys of LUTS prevalence have been conducted in adults. ${ }^{2,17}$ Recently a few paediatric studies using the ICCS definitions have reported LUTS prevalence in children varying from $9.3 \%$ to $46.4 \% .^{7-9}$ The wide variation in prevalence can be attributed to the differences in the study population, questions used to assess LUTS, and the criteria to define the presence of symptoms. Vaz et $\mathrm{al}^{8}$ reported a prevalence of $21.8 \%$ in 739 Brazilian children aged 6 to 12 years while Yüksel et $\mathrm{al}^{7}$ found $9.3 \%$ of 
TABLE 3. Comparison of control subjects with psychotropic substance users

\begin{tabular}{|c|c|c|c|}
\hline & \multicolumn{2}{|r|}{ No. (\%) } & \multirow[t]{2}{*}{$P$ value } \\
\hline & Control subjects $\left(n^{*}=11617\right)$ & Psychotropic substance users $\left(n^{*}=321\right)$ & \\
\hline Age-group (years) & & & $<0.001$ \\
\hline$<13$ & $1545 / 11530(13.4)$ & $37 / 286$ (12.9) & \\
\hline $13-15$ & $5858 / 11530(50.8)$ & $105 / 286(36.7)$ & \\
\hline $16-17$ & $3525 / 11530(30.6)$ & $99 / 286(34.6)$ & \\
\hline$\geq 18$ & $602 / 11530(5.2)$ & $45 / 286(15.7)$ & \\
\hline Missing & $87 / 11617(0.7)$ & $35 / 321(10.9)$ & \\
\hline Gender & & & $<0.001$ \\
\hline Male & $5848 / 11551(50.6)$ & $192 / 308(62.3)$ & \\
\hline Female & $5703 / 11551(49.4)$ & $116 / 308(37.7)$ & \\
\hline Missing & $66 / 11617(0.6)$ & $13 / 321(4.0)$ & \\
\hline Any LUTS & & & $<0.001$ \\
\hline Yes & 2106/11 405 (18.5) & $149 / 312(47.8)$ & \\
\hline Missing & $212 / 11617(1.8)$ & 9/321 (2.8) & \\
\hline Urinary frequency & & & $<0.001$ \\
\hline Yes & $1180 / 11552(10.2)$ & $108 / 313(34.5)$ & \\
\hline Missing & $65 / 11617(0.6)$ & $8 / 321(2.5)$ & \\
\hline Nocturia $\geq 2$ times per night & & & $<0.001$ \\
\hline Yes & $508 / 11537(4.4)$ & $93 / 310(30.0)$ & \\
\hline Missing & $80 / 11617(0.7)$ & $11 / 321(3.4)$ & \\
\hline Urgency & & & $<0.001$ \\
\hline Yes & $338 / 11556(2.9)$ & $81 / 312(26.0)$ & \\
\hline Missing & $61 / 11617(0.5)$ & 9/321 (2.8) & \\
\hline Daytime urinary incontinence $†$ & & & $<0.001$ \\
\hline Yes & $160 / 4302(3.7)$ & 24/127 (18.9) & \\
\hline Missing & 23/4325 (0.5) & $0 / 127(0)$ & \\
\hline Intermittent voiding & & & $<0.001$ \\
\hline Yes & $320 / 11505(2.8)$ & $87 / 314$ (27.7) & \\
\hline Missing & $112 / 11617(1.0)$ & $7 / 321(2.2)$ & \\
\hline Straining & & & $<0.001$ \\
\hline Yes & 213/11 $531(1.8)$ & $82 / 312(26.3)$ & \\
\hline Missing & $86 / 11617(0.7)$ & 9/321 (2.8) & \\
\hline Dysuria & & & $<0.001$ \\
\hline Yes & $210 / 11526(1.8)$ & $84 / 313(26.8)$ & \\
\hline Missing & $91 / 11617(0.8)$ & $8 / 321(2.5)$ & \\
\hline Incomplete emptying & & & $<0.001$ \\
\hline Yes & 628/11 $571(5.4)$ & $91 / 315$ (28.9) & \\
\hline Missing & $46 / 11617(0.4)$ & 6/321 (1.9) & \\
\hline
\end{tabular}

Abbreviation: LUTS = lower urinary tract symptoms

* Subgroups $n$ might or might not equal to total $n$ due to missing values

† Due to printing error, only 4452 of the I I 938 eligible questionnaires included the question on daytime urinary incontinence

their 4016 Turkish children aged 6 to 15 years had or absence of LUTS.7.8 In contrast, Chung et $\mathrm{al}^{9}$ LUTSs. In both studies, the investigators used investigated 16516 Korean children aged 5 to 13 validated scoring systems for a combination of years by measuring the presence of individual LUTSs being assessed and pre-determined cut-off LUTS and reported the highest prevalence of $46.4 \%$ points in the total scores to define the presence experiencing at least one LUTS. The high prevalence 
TABLE 4. Comparison of ketamine users with non-ketamine substance users, and male with female ketamine users

\begin{tabular}{|c|c|c|c|c|c|c|}
\hline & \multicolumn{2}{|c|}{ No. (\%) } & \multirow[t]{2}{*}{$P$ value } & \multicolumn{2}{|c|}{ No. (\%) } & \multirow[t]{2}{*}{$P$ value } \\
\hline & $\begin{array}{l}\text { Ketamine users } \\
\qquad\left(n^{*}=139\right)\end{array}$ & $\begin{array}{c}\text { Non-ketamine } \\
\text { substance users } \\
\left(n^{\star}=166\right)\end{array}$ & & $\begin{array}{l}\text { Male ketamine } \\
\text { users }\left(n^{\star}=75\right)\end{array}$ & $\begin{array}{c}\text { Female ketamine } \\
\text { users }\left(n^{*}=59\right)\end{array}$ & \\
\hline Age-groups (years) & & & 0.41 & & & 0.22 \\
\hline$<13$ & $12 / 114(10.5)$ & 24/160 (15.0) & & 6/61 (9.8) & 6/53 (11.3) & \\
\hline $13-15$ & $39 / 114$ (34.2) & $62 / 160$ (38.8) & & 25/61 (41.0) & $14 / 53(26.4)$ & \\
\hline $16-17$ & $41 / 114$ (36.0) & $52 / 160$ (32.5) & & 22/61 (36.1) & 19/53 (35.8) & \\
\hline$\geq 18$ & 22/114 (19.3) & $22 / 160$ (13.8) & & $8 / 61(13.1)$ & $14 / 53(26.4)$ & \\
\hline Missing & 25/139 (18.0) & 6/166 (3.6) & & $14 / 75(18.7)$ & 6/59 (10.2) & \\
\hline Gender & & & 0.03 & NA & NA & NA \\
\hline Male & $75 / 134$ (56.0) & $109 / 160(68.1)$ & & & & \\
\hline Female & $59 / 134(44.0)$ & $51 / 160$ (31.9) & & & & \\
\hline Missing & $5 / 139$ (3.6) & 6/166 (3.6) & & & & \\
\hline Any LUTS & & & $<0.001$ & & & 0.002 \\
\hline Yes & $82 / 135(60.7)$ & $65 / 162(40.1)$ & & $35 / 73(47.9)$ & $42 / 57(73.7)$ & \\
\hline Missing & 4/139 (2.9) & 4/166 (2.4) & & $2 / 75(2.7)$ & 2/59 (3.4) & \\
\hline Urinary frequency & & & $<0.001$ & & & 0.03 \\
\hline Yes & $63 / 134(47.0)$ & 43/164 (26.2) & & 27/73 (37.0) & $31 / 56(55.4)$ & \\
\hline Missing & 5/139 (3.6) & 2/166 (1.2) & & $2 / 75(2.7)$ & $3 / 59(5.1)$ & \\
\hline Nocturia $\geq 2$ times per night & & & $<0.001$ & & & 0.008 \\
\hline Yes & 57/132 (43.2) & 34/163 (20.8) & & 23/71 (32.4) & $29 / 56(51.8)$ & \\
\hline Missing & $7 / 139(5.0)$ & $3 / 166(1.8)$ & & $4 / 75(5.3)$ & $3 / 59(5.1)$ & \\
\hline Urgency & & & $<0.001$ & & & 0.04 \\
\hline Yes & $50 / 135$ (37.0) & $30 / 162$ (18.5) & & $20 / 74(27.0)$ & $25 / 56(44.6)$ & \\
\hline Missing & 4/139 (2.9) & 4/166 (2.4) & & $1 / 75(1.3)$ & $3 / 59(5.1)$ & \\
\hline Daytime urinary incontinence $†$ & & & 0.09 & & & 0.90 \\
\hline Yes & $13 / 47(27.7)$ & $11 / 73(15.1)$ & & $8 / 30(26.7)$ & $4 / 16(25.0)$ & \\
\hline Missing & $0 / 47(0)$ & $0 / 73(0)$ & & $0 / 30(0)$ & $0 / 16(0)$ & \\
\hline Intermittent voiding & & & $<0.001$ & & & 0.01 \\
\hline Yes & $56 / 136(41.2)$ & $30 / 163$ (18.4) & & 22/74 (29.7) & $29 / 57(50.9)$ & \\
\hline Missing & $3 / 139$ (2.2) & 3/166 (1.8) & & $1 / 75(1.3)$ & 2/59 (3.4) & \\
\hline Straining & & & 0.001 & & & 0.17 \\
\hline Yes & $50 / 133(37.6)$ & $32 / 164$ (19.5) & & 22/73 (30.1) & $23 / 55(41.8)$ & \\
\hline Missing & $6 / 139(4.3)$ & 2/166 (1.2) & & $2 / 75(2.7)$ & $4 / 59(6.8)$ & \\
\hline Dysuria & & & 0.009 & & & 0.11 \\
\hline Yes & 48/136 (35.3) & 35/162 (21.6) & & 20/74 (27.0) & $23 / 57(40.4)$ & \\
\hline Missing & $3 / 139$ (2.2) & $4 / 166(2.4)$ & & $1 / 75$ (1.3) & 2/59 (3.4) & \\
\hline Incomplete emptying & & & $<0.001$ & & & 0.003 \\
\hline Yes & $55 / 136(40.4)$ & 35/164 (21.3) & & 20/74 (27.0) & $30 / 57$ (52.6) & \\
\hline Missing & 3/139 (2.2) & 2/166 (1.2) & & $1 / 75(1.3)$ & $2 / 59$ (3.4) & \\
\hline
\end{tabular}

Abbreviations: LUTS = lower urinary tract symptoms; NA = not applicable

* Subgroups n might or might not equal to total $n$ due to missing values

† Due to printing error, only 4452 of the I 938 eligible questionnaires included the question on daytime urinary incontinence

rate in the Korean study can be partly explained by "no" and a positive symptom was defined without their methodology wherein the responses to the considering its frequency. ${ }^{9}$

LUTS questions were dichotomised into "yes" or To the best of our knowledge, the present 
study is the first large-scale prevalence study focused on adolescents. We used a similar methodology to other major adult studies to measure each LUTS individually and define its presence by a frequency threshold of ' $\geq 20 \%$ of the time.,2,17-19 We agree with others that using a scoring system to define LUTS in a prevalence study may not reflect the true impact of individual LUTS as it is possible that a highly prevalent symptom may happen alone and the summed score may not reach the threshold. ${ }^{17}$

In our adolescents without any substance abuse, $18.5 \%$ experienced at least one LUTS. Our finding suggests that LUTS prevalence in adolescents appears to be lower than that in young adults. Previous studies including two conducted in Chinese populations have reported that $17 \%$ to $42 \%$ of men and women aged 18 to 39 years experience at least one LUTS. ${ }^{2,18,19}$ Notably, LUTS prevalence increased with age during adolescence from $13.9 \%$ in those $<13$ years to $25.8 \%$ in those aged $\geq 18$ years in this study. In children, the prevalence of LUTS peaks at age 5 to 7 years and then declines with increasing age up to 13 to 14 years..$^{7-10,20}$ The decline in prevalence has been attributed to the maturation of urinary bladder function along with the growth and development of children. Our study is the first to provide evidence that LUTS prevalence rises from the trough at the onset of adolescence and continues to increase throughout adolescence into adulthood. Our reported prevalence of $25.8 \%$ in those participants aged $\geq 18$ years is in agreement with the trend in young adults reported elsewhere. ${ }^{2,18,19}$

Little is known in the existing literature regarding the trend of LUTS prevalence from adolescence to adulthood. In a Finnish study of 594 subjects aged 4 to 26 years, the authors reported that individuals aged 18 to 26 years had more urgency than the other two age-groups of 8 to 12 years and 13 to 17 years..$^{10}$ Although adolescence spans less than a decade, it is unique with rapid physical, psychological, and developmental changes. Reasons for the increase in LUTS prevalence from adolescence to young adulthood are largely unknown but likely to be multifactorial. Changes in lifestyle, altered micturition behaviour, habitual postponement of micturition, unhealthy bowel habits, attitudes to the use of school toilets, anxiety associated with academic expectations, or worsening of relationships with family may all contribute to newly developed LUTS during adolescence. Further studies are warranted to investigate this phenomenon.

Our findings that storage symptoms were more prevalent than voiding symptoms are in agreement with the reported results in young adults.,18,19 Urinary frequency $(10.2 \%)$ and nocturia $\geq 2$ times per night (4.4\%) were the two most prevalent storage symptoms among the control subjects. We agree with others that nocturia once per night is very common in the general population and using the threshold of nocturia $\geq 2$ times per night as LUTS is more appropriate..$^{2,17-19}$ Only $2.9 \%$ of our control subjects had urgency suggestive of overactive bladder $(\mathrm{OAB})$ according to ICCS definitions, ${ }^{6}$ in contrast to $12 \%$ of Korean children aged 13 years..$^{20}$ Children with $\mathrm{OAB}$ may have urinary frequency in addition to urgency. The much lower prevalence of urgency than urinary frequency in our study suggests that many of our study subjects had urinary frequency unrelated to OAB. Glassberg et $\mathrm{al}^{21}$ found over $70 \%$ of their paediatric patients with dysfunctional voiding (DV) and primary bladder neck dysfunction (PBND) experienced urinary frequency; DV and PBND are also associated with high residual urine volume. Our finding that the feeling of incomplete emptying (5.4\%) was the second most prevalent LUTS suggests that in some participants urinary frequency was secondary to incomplete bladder emptying associated with DV or PBND.

In our study, male non-substance users experienced more voiding symptoms while females had more daytime UI. Literature has consistently found female gender to be a risk factor for daytime UI in children., ${ }^{5,22,23}$ Our finding suggests that the gender association with daytime UI extends from childhood to adolescence. There are inconsistencies in the paediatric literature with respect to gender differences in voiding symptoms. Kyrklund et $\mathrm{al}^{10}$ found more voiding symptoms in boys than girls only in the age-group of 4 to 7 years, while such difference was not noted by others. ${ }^{8,24}$

Psychotropic substance use increased the risk of LUTS in our adolescents. Notably, $60 \%$ of our adolescents who abused ketamine had experienced at least one LUTS and had high prevalence rates of $28 \%$ to $47 \%$ in all areas of LUTS. Our finding that $2.7 \%$ of our participants abused psychotropic substances is consistent with the latest figure of $2.3 \%$ estimated by our government in its survey conducted in 2011/12. ${ }^{15}$ Ketamine-associated uropathy has emerged as a new clinical entity in our society since $2007 .{ }^{13}$ This chemically induced cystitis as a result of the urinary metabolites of ketamine is associated with severe LUTS with the possible consequence of irreversible bladder damage. ${ }^{12,25}$ Little information is available in the medical literature about the prevalence of LUTS among ketamine users. An online survey conducted in the UK reported a prevalence of $26.6 \%$ of at least one LUTS in the last 12 months among 1285 participants who had illicitly used ketamine. ${ }^{26}$ The LUTS prevalence is likely influenced by variation in dose and frequency of ketamine use of the study population. We have recently reported that both the dose and frequency of ketamine use and female gender are associated with the severity of the LUTS at presentation among the young patients who sought urological treatment for ketamine-associated 
uropathy. ${ }^{25}$ In the present study, female ketamine users were at a higher risk of developing LUTS than males. This observation is in agreement with our previous findings and our postulation that females appear to be more susceptible to the chemically induced injury following illicit use of ketamine for unknown reasons. ${ }^{25}$

Non-ketamine substance users also experienced more LUTSs than the control subjects in this study although the prevalence was not as high as that of ketamine users. Most recently Korean investigators have reported a $77 \%$ prevalence rate of LUTS among a group of young methamphetamine (also known as 'ice') users, and suggested that a pathological dopaminergic mechanism plays a predominant role in methamphetamine-associated LUTS. $^{27}$ There has been a rising trend of using methamphetamine in recent years and it is now the second most popular psychotropic substance abused by youths aged $<21$ years in our community. ${ }^{14}$ It would not be surprising if we encountered more and more young patients presenting with LUTS associated with methamphetamine use in the foreseeable future.

\section{Limitations of this study}

There was potential bias in the sampling process as almost two thirds of the schools that we selected and approached refused to participate, the grades of the participants were not randomly selected, and non-response rate was approximately $20 \%$. Young participants of lower grades may not be able to comprehend the LUTS questions that were designed for adults. Nevertheless, our finding of $2.7 \%$ of psychotropic substance use appears to be consistent with the $2.3 \%$ reported by the 2011/12 government survey in over 80000 secondary school students. ${ }^{15}$ We did not study other potential risk factors that may be associated with LUTS in adolescents such as bowel function, urinary tract infection, stressful events, lifestyle, and toilet environment. The $0.5 \%$ to $2 \%$ missing data in each of the LUTS questions, though small, may still affect the estimated prevalence of each LUTS among our control subjects. Although daytime UI was not a prevalent symptom, the fact that less than half of the participants were asked this question because of a printing error may underestimate the overall prevalence of experiencing at least one LUTS among different subgroups. The 4-week recall period only allowed crude assessment of LUTS. A more-prevalent symptom may not necessarily cause more inconvenience than a lessprevalent symptom. How each individual LUTS concerned the participant and how different the substance abusers and non-substance abusers were concerned by the LUTS were not investigated in this study. Therefore individuals, particularly the nonsubstance abusers, who reported the experience of LUTS did not necessarily suffer from any established lower urinary tract conditions that warranted medical attention. The dose and frequency of illicit psychotropic substance use would certainly have an impact on the prevalence of LUTS but this was not investigated in this survey.

Despite all these limitations, our study provides important data on the prevalence of LUTS in adolescents and the effect of psychotropic substance use. The LUTSs are prevalent in the general adolescent population. It is important for clinicians to obtain a history about psychotropic substance use when treating teenagers with LUTS as there is a substantial possibility that the LUTSs are caused by organic pathology associated with psychotropic substance use and not functional voiding disorders.

\section{Appendix}

Additional material related to this article can be found on the HKMJ website. Please go to <http:// www.hkmj.org $>$, and search for the article.

\section{Declaration}

The study was supported by the Beat Drugs Fund (BDF101012) of the Hong Kong SAR Government. The funding source had no role in the study design, data collection, data analysis, results interpretation, writing of the manuscript, or the decision to submit the manuscript for publication. All authors have no conflicts of interest relevant to this article to disclose.

\section{References}

1. Irwin DE, Kopp ZS, Agatep B, Milsom I, Abrams P. Worldwide prevalence estimates of lower urinary tract symptoms, overactive bladder, urinary incontinence and bladder outlet obstruction. BJU Int 2011;108:1132-8.

2. Irwin DE, Milsom I, Hunskaar S, et al. Population-based survey of urinary incontinence, overactive bladder, and other lower urinary tract symptoms in five countries: results of the EPIC study. Eur Urol 2006;50:1306-14; discussion 1314-5.

3. Koff AS, Wagner TT, Jayanthi VR. The relationship among dysfunctional elimination syndromes, primary vesicoureteral reflux and urinary tract infections in children. J Urol 1998;160:1019-22.

4. Leonardo CR, Filgueiras MF, Vasconcelos MM, et al. Risk factors for renal scarring in children and adolescents with lower urinary tract dysfunction. Pediatr Nephrol 2007;22:1891-6.

5. Sureshkumar P, Jones M, Cumming R, Craig J. A population based study of 2,856 school-age children with urinary incontinence. J Urol 2009;181:808-15; discussion 815-6.

6. Nevéus T, von Gontard A, Hoebeke P, et al. The standardization of terminology of lower urinary tract function in children and adolescents: report from the Standardization Committee of the International Children's Continence Society. J Urol 2006;176:314-24.

7. Yüksel S, Yurdakul AC, Zencir M, Cördük N. Evaluation of lower urinary tract dysfunction in Turkish primary schoolchildren: an epidemiological study. J Pediatr Urol 
2014;10:1181-6

8. Vaz GT, Vasconcelo MM, Oliveira EA, et al. Prevalence of lower urinary tract symptoms in school-age children. Pediatr Nephrol 2012;27:597-603.

9. Chung JM, Lee SD, Kang DI, et al. An epidemiologic study of voiding and bowel habits in Korean children: a nationwide multicenter study. Urology 2010;76:215-9.

10. Kyrklund K, Taskinen S, Rintala RJ, Pakarinen MP. Lower urinary tract symptoms from childhood to adulthood: a population based study of 594 Finnish individuals 4 to 26 years old. J Urol 2012;188:588-93.

11. Wood D, Cottrell A, Baker SC, et al. Recreational ketamine: from pleasure to pain. BJU Int 2011;107:1881-4.

12. Chu PS, Ma WK, Wong SC, et al. The destruction of the lower urinary tract by ketamine abuse: a new syndrome? BJU Int 2008;102:1616-22.

13. Chu PS, Kwok SC, Lam KM, et al. 'Street ketamine'associated bladder dysfunction: a report of ten cases. Hong Kong Med J 2007;13:311-3.

14. Central Registry of Drug Abuse Sixty-third Report 20042013. Narcotics Division, Security Bureau, The Government of the Hong Kong Special Administrative Region. Available from: http://www.nd.gov.hk/en/crda_63rd_report.htm. Accessed Dec 2015.

15. The 2011/12 survey of drug use among students. Narcotics Division, Security Bureau, The Government of the Hong Kong Special Administrative Region. Available from: http://www.nd.gov.hk/en/survey_of_drug_use_11-12.htm. Accessed Dec 2015.

16. Yee CH, Li JK, Lam HC, Chan ES, Hou SS, Ng CF. The prevalence of lower urinary tract symptoms in a Chinese population, and the correlation with uroflowmetry and disease perception. Int Urol Nephrol 2014;46:703-10.

17. Coyne KS, Sexton CC, Thompson CL, et al. The prevalence of lower urinary tract symptoms (LUTS) in the USA, the UK and Sweden: results from the Epidemiology of LUTS (EpiLUTS) study. BJU Int 2009;104:352-60.

18. Zhang L, Zhu L, Xu T, et al. A population-based survey of the prevalence, potential risk factors, and symptomspecific bother of lower urinary tract symptoms in adult Chinese women. Eur Urol 2015;68:97-112.

19. Wang Y, Hu H, Xu K, Wang X, Na Y, Kang X. Prevalence, risk factors and the bother of lower urinary tract symptoms in China: a population-based survey. Int Urogynecol J 2015;26:911-9.

20. Chung JM, Lee SD, Kang DI, et al. Prevalence and associated factors of overactive bladder in Korean children 5-13 years old: a nationwide multicenter study. Urology 2009;73:63-7; discussion 68-9.

21. Glassberg KI, Combs AJ, Horowitz M. Nonneurogenic voiding disorders in children and adolescents: clinical and videourodynamic findings in 4 specific conditions. J Urol 2010;184:2123-7.

22. Kajiwara M, Inoue K, Usui A, Kurihara M, Usui T. The micturition habits and prevalence of daytime urinary incontinence in Japanese primary school children. J Urol 2004;171:403-7.

23. Hellström A, Hanson E, Hansson S, Hjälmås K, Jodal U. Micturition habits and incontinence in 7-year-old Swedish school entrants. Eur J Pediatr 1990;149:434-7.

24. Akil IO, Ozmen D, Cetinkaya AC. Prevalence of urinary incontinence and lower urinary tract symptoms in schoolage children. Urol J 2014;11:1602-8.

25. Tam YH, Ng CF, Pang KK, et al. One-stop clinic for ketamine-associated uropathy: report on service delivery model, patients' characteristics and non-invasive investigations at baseline by a cross-sectional study in a prospective cohort of 318 teenagers and young adults. BJU Int 2014;114:754-60.

26. Winstock AR, Mitcheson L, Gillatt DA, Cottrell AM. The prevalence and natural history of urinary symptoms among recreational ketamine users. BJU Int 2012;110:1762-6.

27. Koo KC, Lee DH, Kim JH, et al. Prevalence and management of lower urinary tract symptoms in methamphetamine abusers: an under-recognized clinical identity. J Urol 2014;191:722-6. 